\title{
The Influence of the Balanced Score Card on Performance of Public Sector Organizations in Kenya
}

\author{
Zipporah Karimi Muiruri ${ }^{*}$, James Kilika \\ Department of Business Administration, Kenyatta University, Nairobi, Kenya \\ Email address: \\ zippy.karimi@gmail.com (Z. K. Muiruri), kilikam3@yahoo.com (J. Kilika)
}

To cite this article:

Zipporah Karimi Muiruri, James Kilika. The Influence of the Balanced Score Card on Performance of Public Sector Organizations in Kenya. Science Journal of Business and Management. Vol. 3, No. 5, 2015, pp. 150-156. doi: 10.11648/j.sjbm.20150305.13

\begin{abstract}
The Balanced Score Card model has proved to be an efficient strategic management tool over the years since its development in the early 90s. More and more private sector organizations have adopted its use though public sector pace of its adoption in measuring performance has been slow. The model has been presented on the support of four dimensions that offer a holistic approach for the implementation of organizational strategies so as to balance the concerns of diverse stakeholders to firm performance. The study was therefore designed to establish the extent to which these dimensions have been implemented in some selected public sector organizations in Kenya and how they are likely to explain variation in the performance of the organizations. The study identified four objectives and relevant hypotheses relating each dimension of the BSC with performance of the public sector organizations. The study adopted a descriptive research survey design and drew its population from all state owned corporations in the Ministry of Energy and Petroleum. The respondents were classified into two categories namely officers in charge of performance contracting and heads of departments namely; ICT, Human Resource Management, Finance and Customer service. The researchers used a questionnaire which was designated for the Heads of Departments and for the officers in charge of performance contract exercise too. The descriptive results indicated that Financial, Internal Business Process and Customer Focus were rated relatively high $($ mean $=1.892$, s.d. $=0.7047$; mean $=2.088$, s.d. $=$ 0.728; mean=2.022, 0.6821 respectively). Innovation and learning, however was rated low (mean= 2.892, 0.8422) and Organizational performance was rated at the level of moderate (mean $=3.32$, s.d. $=1.0961)$. The four dimensions explain $71.5 \%$ variation of the performance. The four dimensions significantly predict the performance of the public sector organizations in Kenya. The results indicated a strong relationship between the dependent and independent variables where R2 was $71.5 \%$. The study concluded that the balanced scorecard is not only a measurement system, but also a management tool for use by organizations to clarify their vision and strategy and their translation into goals and actions. The study called on the organizations sampled to carry out thorough capacity building on the application of BSC so that more stakeholders understand and internalize the concept in order to enhance its adoption.
\end{abstract}

Keywords: Balanced Score Card, Finance Perspective, Internal Business Processes, Learning and Innovation, Customer Focus, Public Sector Organizations, Organizational Performance

\section{Introduction}

The Balanced Score Card (BSC) is a system used strategically in business, industry, government and nonprofit organizations worldwide to align business activities to the vision and strategy of organizations. It is meant to improve internal and external communications and monitor organizations' performance against strategic goals. The BSC tool has its origin from the works of Kaplan and Norton [1]. This tool was developed after conducting a study that focused on the failure of financial measures to adequately address organizational performance. The authors recognized that in the realm of knowledge-based competition, the ability of organizations to develop, nurture, and mobilize their intangible assets were critical for success [2]. The primary type of performance measurement used at the time was based on lagging financial indicators, such as return on equity and earnings per share. These antiquated forms of measurement failed to capture the value of operational measures that include employee skills, customer loyalty, and dealer relationships.

The BSC concept has in most countries been preceded by the performance management system. In Kenya, the first 
performance measurement system to be used in the public sector was the Performance Contracting system which was a hybrid borrowed from international practices and the BSC. The Performance Contracting and evaluation system best practices were drawn from USA, UK, Malaysia and South Korea [3]. Kenya Railways Corporation and National Cereals and Produce Board were the first state government agencies to be piloted. The results achieved from these two agencies indicated that there was no adequate linkage between performance contracting and budgeting systems. The performance contract matrices were many hence hindering effective implementation. It was recommended that there was a need for development and adoption of a comprehensive performance measurement system that could incorporate other tools like the BSC Performance Index [3].

The BSC concept has been substantially studied from the corporate sector. Evidence from both online and offsite publications indicate that much more research has been done in the corporate sector than in the public sector. For example, when a search in Scopus was performed on April 20, 2009, the term Balanced Scorecard during 1998-2002, showed 210 studies, but when the term public sector was added only 34 studies was reported. The same search was done on Google Scholar and resulted in 6,590 studies on the term "Balanced Scorecard" and 1,760 when the term public sector was added. In addition most of research has been done in the developed countries such as United States of America, United Kingdom, Malaysia and South Korea [3] as opposed to the developing countries.

Due to the growing interest by the public sector to adopt some of the best practices applied in the private sector, it was considered necessary to assess how the BSC concept is influencing performance in the public sector in Kenya. The general objective of this study was to establish contribution of The Balanced Score Card to the Performance of Public sector Organizations in the Ministry of Energy and Petroleum in Kenya. Specific objectives under study were: to investigate the relationship between the financial perspective of BSC and performance in public sector organizations in the Ministry of Energy and Petroleum in Kenya, to establish the relationship between internal business process perspective of BSC and performance in public sector organizations in the Ministry of Energy and Petroleum in Kenya, to determine the relationship between innovation and learning perspective of BSC and performance in public sector organizations in the Ministry of Energy and Petroleum in Kenya and to find out the relationship between the customer perspective of the BSC and performance in public sector organizations in the Ministry of Energy and Petroleum in Kenya.

\section{Theoretical Review}

The BSC has been widely adopted in several streams of knowledge in management. Evidence exists to show that it is relevant in strategic management. The shareholder value analysis (SVA) model [4], the economic value added (EVA) and market value added (MVA) concepts are the most important developments in financial management research and practice which have resulted into new thinking and refinements to the initial model $[5,6]$.

Rappaport's model indicates that shareholder value is driven by seven factors, namely sales growth, the operating profit margin, the cash tax rate, investment in working capital, investment in fixed assets, the cost of capital and the planning period that is the length of time over which the future cash flow projections are made [7]. Two limitations of the SVA model arise from the difficulty of estimating future cash flows and the absence of a performance measure to which remuneration can be linked. The EVA model is based on the assertion that economic profits have the greatest impact on shareholder value as measured by the MVA and that EVA should therefore be maximized. EVA is a better performance measure than net profit because it is calculated after taking into account the full cost of capital, including an opportunity cost for using equity. The biggest limitation of EVA and also its strength is the fact that it is a single measure of performance. In spite of early reports of good correlation between EVA and MVA [6], research to date has not proved conclusively that EVA correlates better with shareholder wealth than other traditional accounting measures. Support for using the EVA along with, or as part of the balanced scorecard came from Skyrme and Amidon [8].

The financial strategy matrix [9] is a noteworthy financial innovation in the context of finding an appropriate financial perspective. Two variables, namely wealth creation (EVA) and cash management, are used to evaluate a company and to place it in a certain quadrant on the financial strategy matrix. A relative measure of wealth creation, the return spread, is used instead of EVA, and the cash management is measured by the difference between sales growth and the sustainable growth rate [10].

The BSC is not meant to be a tool of substitution but rather, a measurement system that aims to guide and measure the achievements of the organization. It allows managers to convert their vision into clear measures of success [11]. Even though the BSC retains financial measurement as a critical summary of managerial business performance, it highlights a more general and integrated set of measurements that link current customers, internal processes, employees, and system performance for long-term financial success and thus focuses both internally and externally [12].

The external perspective means that the company should analyze how customers perceive the organization, for example by measuring customer satisfaction. The internal perspective means looking inside the organization, spotting where the company must succeed and can be improved. The innovation and learning perspective means examining how the organization grows. And finally the financial perspective includes the financial performance of the organization [13].

$\mathrm{BSC}$ is also described to be a set of measures derived from an organizational strategy that helps management of the organization to communicate the outcomes and performance drivers by which the organization plans to achieve its 
mission and strategic objectives [14]. BSC is a customized communication tool within a management control system applied at different levels of the organization for different strategies [15]. BSC is viewed as a management communication tool that could be used to spread the vision of the organization to its stakeholders and to communicate and measure the success of the strategy [12]. The divergent results obtained from using BSC have prompted researchers to actually look into other variables that can lead to a successful implementation of the BSC. Factors like the skills of the in-house IT staff support from top management, extent of business process redesign (BPR) and the IT infrastructural compatibility impact enterprise resource planning (ERP) system adoption. Most ERP applications have a module for BSC and such applications have been used to influence BSC adoption success at the organizational level [16].

\subsection{The Balanced Score Card Concept}

The BSC can be thought of as the strategic chart of accounts for an organization. It captures both the financial and the non-financial elements of an organization's strategy and discusses the cause and effect relationships that drive business results [2].The four elements include financial perspective, internal business process perspective, learning and innovation perspective and the customer focus perspective.

The Financial perspective examines if an organization's implementation and execution of its strategy are contributing to the bottom line improvement. The three possible stages [12] are rapid growth, sustainability and harvest. The financial perspective can be analyzed in form of; cash flow, sales growth, operating income, market share and return of equity (ROE) [1]. Data development Analysis was used to measure tradeoffs between different balanced score card metrics in the telecommunication industry. Trade-offs was found unlikely to exist between different metrics in a balanced scorecard thus conclusion that measures that require trade-off with financial measures should be included in the balanced scorecard [17].

Internal Business perspective is concerned with the processes that create and deliver the organization's customer value proposition. In order to identify the measures that correspond to the internal process perspective, Kaplan and Norton suggested the use of certain clusters that group similar value creating processes in an organization which are operations, customer, regulatory and social. The internal process perspective is based on the notion that to satisfy customers and earn a financial return, the business must be efficient and effective at what it does. Its' measures are typically based on the objective of most efficiently and effectively producing order conversion rate, on-time delivery from suppliers, cost of non-conformance and lead-time reduction [18]. Internal pressures rest on taken-for-granted assumptions that are embedded in the firms operations built on past experiences, power relations, inertia, common beliefs and memories [19]. A benchmarking study found that when a company emphasizes active participation among all personnel in gathering intelligence, the competitive intelligence function within that company is viewed as more effective by $40 \%$ of the management participants [20]. It is necessary to classify competitive activities as either strategic or tactical in order to measure effectiveness. Evaluation of strategic competitive output would measure the proportion of accurate to inaccurate predictions of the future. A blend of both strategic and tactical approaches along with consumer satisfaction ratings will produce an effective method for competitive departments to demonstrate accountability for the work they produce as an internal process perspective of the Balanced Score Card [21].

The Innovation and learning element has been presented as the foundation of any strategy and focuses on the intangible assets of an organization, mainly on the internal skills and capabilities that are required to support the value creating internal processes. It is concerned with human capital, the information systems and the organization capital of the firm. The learning process should focus on the acquisition of managerial competencies that permit the organization to stay ahead of competitors [22]. Organizational learning can be categorized in two related processes; knowledge acquisition and knowledge conversion [23]. The first is linked to the individual level and the second to the organizational level. Organizational learning is also proposed to be comprising of four learning activities [14]: knowledge acquisition comprising the development or creation of skills, insight, relationships; knowledge sharing which is the dissemination to others of what has been acquired by some; knowledge utilization which is the integration of the learning so that it is assimilated, broadly available and can also be generalized to new situations and unlearning which is the review and renewal of existing knowledge and communication of changes within the firm.

The Customer focus perspective includes general measures from the desired successful outcomes of a wellformulated and implemented strategy. The core measures may include overall indicators such as customer satisfaction, customer complaints, customers lost or won on-time delivery and sales from new products [24]. Measures related to customers include results from customer surveys, sales from repeat customer and customer profitability. Customer perspective is observed as the core of any business strategy which describes the unique mix of product, price, service, relationship and image that a company offers [2]. The customer perspective defines how the organization differentiates itself from competitors to attract, retain and deepen relationships with targeted customers. The value of the customer perspective is crucial because it helps an organization connect its internal process to improved outcomes with its customers. There are differences between customers' perceptions and expectations and its level of differences varies among industries [25, 26, 27]. Management should use their utmost efforts to meet and exceed customer expectation by excelling in service delivery and by being great at service recovery. On the marketing side it is advisable that management should focus on new efforts 
and paradigm shift towards working more closely with customers to clarify their expectations. In most organizations, marketers are now required to be innovative and develop new ways of helping their organizations meet and exceed customer expectations [28,29].

\subsection{Organizational Performance}

BSC is used as an information system, implying that there are no targets to measure and no one is accountable for the measure, but when the scorecard is used as a MBO tool [2], the measures are derived on the key performance indicators (KPI). The KPI are measures which the organizations must excel for them to realize their visions. BSC measures can be derived from the business strategy, in which situations the business strategy is seen as a series of cause and effect relationship between different perspectives and measures in the BSC. For instance if an organization aims at maximizing its return on capital employed (ROCE) which is a lagging indicator of performance, then the rest of the measures will include process quality, on-time delivery and loyal customer base as the indicators that will lead the organization towards attaining the ROCE goal. For the realization of higher ROCE, the company then ought to train its employees to perform better. Better training will reflect in the process quality, ontime delivery of services, satisfied customers, revenue increases and higher ROCE for the firm. The amount of measure to be included in the scorecard varies depending on the purpose for using the BSC. Thus the financial perspective parameters under this study were; revenue collection, earnings, returns on capital, cash flow and operating income $[1,2,3,12]$. Under the internal business process perspective: productivity rates, quality measures, timeliness, competitive and market intelligence were investigated. Learning and innovation investigated the percent of revenue from new products, employees' suggestions, and rate of improvement index, organizational learning and internal promotion rate. The customer focus perspective studied customer satisfaction measures, customer loyalty, market share, organization's service charter and customer relationship mechanisms.

\section{Research Conceptualization and Hypotheses}

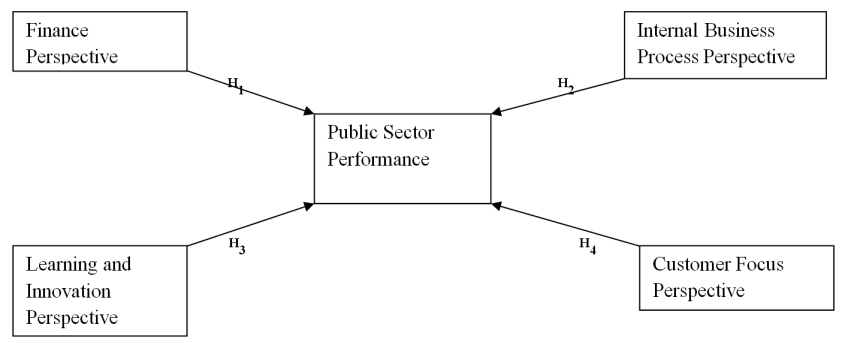

Figure 1. Conceptual Model Relating BSC Components with Firm Performance.

Using the arguments in the previous section capturing both theoretical and empirical literature, the study proposed a simple conceptual model that related the components of the BSC as independent variables with the dependent variable of performance. The conceptual framework is shown in figure 1.

Organizations adopt the BSC elements to drive performance. Public sector organizations that have implemented strategic management and operationalised the expected outcomes using the BSC indicators are expected to register positive performance. Thus, it is proposed BSC elements will have a favorable influence on the performance of the public sector organizations in Kenya. The study proposed that:

- Hypothesis one: There is a relationship between the financial perspective element of the BSC and performance of public sector organizations in Kenya.

- Hypothesis two: There is a relationship between internal business process perspective element of the BSC and performance of public sector organizations in Kenya.

- Hypothesis three: There is a relationship between learning and growth perspective element of the BSC and performance of public sector organizations in Kenya.

- Hypothesis four: There is a relationship between customer focus perspective element of the BSC and performance of public sector organizations in Kenya.

\section{Methodology}

\subsection{Research Design and Population}

Descriptive research design was used to carry out the survey. The information was collected without changing or manipulating the environment and able to demonstrate the relationship between the BSC perspectives and performance in the sampled organizations. The target population for the study included ten state owned corporations in the Ministry of Energy and Petroleum in public sector in Kenya. The respondents were the heads of the four departments in each of the sampled organizations plus officers in charge of Performance Contracting totaling to five respondents in each organization. The researchers used purposive sampling technique exclusively. In this respect the researcher collected data from only those state owned corporations that are known to have used BSC in their performance evaluation. The study selected the ten state owned corporations in the Ministry of Energy and Petroleum whereby 5 departments in each comprising the Performance Contracting, Information Communication and Technology, Human Resource Management, finance and customer service formed the respondents. The data for drawing the sampling frame was obtained from the Kenya National Bureau of Statistics [30]. In total 50 respondents were targeted and interviewed.

\subsection{Instrumentation}

The study relied on a structured questionnaire as the main instrument for collecting primary data. The questionnaire was structured on a 5- point likert scale to obtain information on all 
the variables in the study. The specific items in the questionnaire were drawn from relevant theoretical and empirical literature to ensure that aspects of face, construct and content validity are complied with. The instrument was pre tested using postgraduate students enrolled in various programs in Kenyatta University in Kenya to ensure reliability and consistency in the instrument, reliability tests were done on all sections of the questionnaire and the cronbach alpha score of at least 0.7 used as cut-off point. The instrument was administered to the respondents through personal interviews.

\subsection{Data Analysis}

Descriptive analysis was employed to analyze the data. Tables and other graphical presentations as appropriate were used to present the data collected for ease of understanding and analysis. Tables were used to summarize responses for further analysis and facilitate comparison. This helped to generate quantitative reports through tabulations, percentages, and measure of central tendency. The study used both descriptive and inferential statistics. The mean score for each variable was calculated and the standard deviation used to interpret the respondents deviation from the mean. Here the interest was focused on frequency of occurrence across attributes of measures. Under the inferential analysis, a regression model was applied to determine the relative importance of each of the variables with respect to performance of organizations in the public sector in Kenya. Regression analysis was used because it would help indicate if the independent variables have a significant relationship with the dependent variable and the relative strength of different independent variables' effect on the dependent variable.

\section{Results}

Both descriptive analysis and inferential statistics were used to analyze the data. In the descriptive statistics, relative frequencies were used in some questions and in inferential statistics.

\subsection{Demographic Data}

The 50 respondents comprised $40 \%$ males and $60 \%$ females. Those aged below 30 years were $12 \%, 31$ to 40 were $50 \%, 41$ to 50 were $22 \%, 51$ to 60 were $12 \%$ and above 60 were $4 \%$. On years of working experience, $24 \%$ had less than 5 years, $18 \%$ had between 6 and 10 years, $46 \%$ had worked for between 11 and 15 years, $8 \%$ had worked for between 16 and 20 years while $4 \%$ had worked for 21 years and above. Respondents' understanding level of application of the BSC was high at $58 \%$, moderate at $20 \%$, very high at $12 \%$ and poor at $10 \%$.

\subsection{Descriptive Analysis}

The descriptive analysis of the findings in the table below provides a summary of analysis about observations that have been made. The likert scale questionnaire had 5 items in all the independent variables and 10 items for the dependent variable with 1 being the highest and 5 the lowest. The mean was used as a measure of central tendency while standard deviation measured variability to describe the characteristics of responses on each variable.

Table 1. Summary of the findings.

\begin{tabular}{lllll}
\hline BSC element & No. of items & Mean & Standard Deviation & Interpretation \\
\hline Finance Perspective & 5 & 1.892 & 0.7047 & High \\
Internal Business Processes Perspective & 5 & 2.088 & 0.7280 & High \\
Innovation and Learning Perspective & 5 & 2.892 & 0.8422 & Moderate \\
Customer Focus Perspective & 5 & 2.0200 & 0.6821 & High \\
Business Organizational Performance & 10 & 3.3200 & 1.0961 & Moderate \\
\hline
\end{tabular}

\subsection{Test of Hypotheses}

The study tested four hypotheses from the conceptual framework. The results of the test of the four hypotheses are summarized in the regression model analysis in table 2 and expressed as $\mathrm{Y}=3.938+0.205 \mathrm{X}_{1}+0.771 \mathrm{X}_{2}+0.344 \mathrm{X}_{3}+$ $1.024 \mathrm{X}_{4}$. The results show that the four variables explain a relatively high proportion of the variation in the performance of public sector organizations investigated in the study $\left(\mathrm{R}^{2}=\right.$ $0.715)$. All the firms' variables positively predict variation in the performance of public sector organizations as: Financial perspective $(\beta=0.205 ; \mathrm{t}=2.015 ; \rho<0.05)$ : Internal business process perspective $(\beta=0.771 ; t=5.870 ; \rho<0.001)$; Innovation and learning perspective $(\beta=0.344 ; \mathrm{t}=3.874 ; \rho<0.001)$ and Customer focus perspective $(\beta=1.024 ; \mathrm{t}=8.419 ; \rho<0.001)$. The multiple regression model expressing this relationship is significant $(\mathrm{F}=28.186 ; \mathrm{P}<0.001)$. The study therefore, concludes that each of the four perspectives of the BSC have a positive relationship with the performance of public sector organizations in Kenya.

These findings reported are consistent with previous research findings by Andy et al.,[31] who found out that implementation of the BSC had a positive impact on sales, gross profit and net profit. In another study carried out by Barbara and Eleonora, [32], the results also agree with the current study findings whereby companies examined had a similar view for three of the four perspectives of BSC which can be thus considered as validated. Similar to their findings, the innovation and learning dimension had the lowest mean score. Also in a study carried out by sanjoy and keith [33], findings concur with results herein. Foster group; the organization under study had undergone successful diversification, cost reductions, improvement in productivity and innovation leading to immense growth that made them 
emerge one of the world's leading brewers by applying the BSC. In another study [34], findings show that the benefits of balanced score card outweigh the costs if implemented fully, efficiently and effectively and that it complements the financial measures of past performance with operational measures that drive future performance and growth.

Table 2. Strength of the Relationship between BSC and Performance.

Model Summary ${ }^{\mathrm{b}}$

\begin{tabular}{|c|c|c|c|c|c|}
\hline \multirow{2}{*}{ Model } & \multirow{2}{*}{$\mathbf{R}$} & \multirow{2}{*}{ R Square } & \multirow{2}{*}{ Adjusted R Square } & \multirow{2}{*}{ Std. Error of the Estimate } & Change Statistics \\
\hline & & & & & R Square Change \\
\hline 1 & $.845^{\mathrm{a}}$ & .715 & .689 & .71001 & .715 \\
\hline
\end{tabular}

\begin{tabular}{|c|c|c|c|c|c|c|c|}
\hline \multicolumn{7}{|c|}{ Coefficients $^{\mathrm{a}}$} & \multirow{3}{*}{ Conclusion } \\
\hline \multirow{2}{*}{\multicolumn{2}{|c|}{ Model }} & \multicolumn{2}{|c|}{ Unstandardized Coefficients } & \multirow{2}{*}{$\begin{array}{l}\text { Standardized Coefficients } \\
\text { Beta }\end{array}$} & \multirow{2}{*}{$\mathbf{t}$} & \multirow{2}{*}{ Sig. } & \\
\hline & & B & Std. Error & & & & \\
\hline \multirow{5}{*}{1} & (Constant) & 3.938 & .427 & & 9.233 & .000 & \\
\hline & Financial Perspective & .294 & .146 & .205 & 2.015 & .050 & $\mathrm{H}_{1}$ Supported \\
\hline & Internal Business Process Perspective & 1.423 & .242 & .771 & 5.870 & .000 & $\mathrm{H}_{2}$ Supported \\
\hline & Innovation and learning perspective & .556 & .144 & .344 & 3.874 & .000 & $\mathrm{H}_{3}$ Supported \\
\hline & Customer Focus perspective & 1.369 & .163 & 1.024 & 8.419 & .000 & $\mathrm{H}_{4}$ Supported \\
\hline
\end{tabular}

\section{Implications for Theory and Practice}

The findings of the study are interpreted in view of the relevant theoretical and empirical literature that underpinned the study. The descriptive results showed that three dimensions of the BSC model have been adopted to a high extent in terms of the scale used in this study. One item however, has been adopted to a low extent touching on Innovation and learning. Given the sector where the study was done, it may be possible to explain the relatively low score on innovation due to the prevailing bureaucratic cultural environment of the sector which may not offer a lot of opportunities for individuals to exercise their creativity.

The test of the four hypotheses showed that the BSC model components are positively related with performance of public sector organizations. The positive association between these dimensions may be explained from several points of view. First, using the strategic management literature; the study observes that this association may derive from the ability of the model to balance among diverse stakeholders interests. The strategic management literature is increasingly prioritizing the need to adopt a stakeholder orientation both in choice and implementation of strategies. Interpreted in this manner, therefore, the findings are found to enhance the postulates of the stakeholder management theory [14].

Secondly, even though these findings explain a relatively high proportion of the performance, it is notable that $29 \%$ of the variation was attributed to other factors outside the scope of this study. The authors are of the view that the BSC when implemented will influence performance in the context of each organization through other intermediate conditions by which the organizations builds capabilities to drive performance. Thus there are possibilities of both internal and external forces influencing as moderating or mediating factors such as resources.

\section{Conclusion}

The findings and discussions presented in this study lead to several conclusions. First, the fact that a $71 \%$ variation in performance is attributed to the BSC components leads to the conclusion that the BSC as a tool for use in strategic management is relevant for application in the public sector. Secondly, the findings confirm that the theoretical underpinnings for the adoption of the BSC based on the stakeholders' perspective in the private sector have a role to play in guiding strategic management practices in the public sector organizations. Thirdly, it may be concluded that despite structural and cultural differences between the private and public sectors, there are areas of commonality when it comes to the application of strategic management theory to inform management practices.

\section{Recommendations for Further Research}

The findings reported in the study face some limitations. First, the study was not done as a census of all state owned corporations in Kenya. Secondly, in the conceptualization, the study did not provide and test for the possibility of mediating conditions brought about by the BSC within organizational processes as well as the moderating role of the context of the organizations studied. Further research can consider the relationship between the four components of the BSC with performance while providing for the influence of mediating and moderating conditions using a larger sample of state owned corporations. 


\section{References}

[1] Kaplan, R.S. \& Norton, D.P., (1992). The balanced scorecard - measures that drive performance, Harvard Business Review.

[2] Kaplan, R.S. \& Norton, D.P., (2001b). The Strategy-focused Organization: Harvard Business School Press. Boston. MA.

[3] World Bank (2004). Adjustment in Africa Reforms, Results and the Road ahead. Oxford University Press.

[4] Rappaport, A., (1986). Creating Shareholder Value. New York: Free Press.

[5] Stewart, F., (1991). Performance Measures: An application of Economic Value Added. International Journal of Business and Management. 3(3).

[6] Brown, C., Reich, M., \& Stern, D., (1993). Becoming a high performance work organization: the role of security, employee involvement and training. The International Journal of Human Resource Management, 4(2).

[7] Barsky, N.P. \& Bremser, W.G., (1999). Performance measurement, budgeting and strategic implementation in the multinational enterprise. Managerial Finance, 25(2).

[8] Skyrme D.J., \& Amidon D.M., (1998). New measures of success, Journal of Business Strategy, 19(1).

[9] Hawawini T.L, \& Viallet D.E., (1999). An appropriate Financial Perspective for a Balanced Scorecard. Southern African Business Review. Unisa Press. 11(2).

[10] Sim, K.L, \& Koh, H.C., (2001). Balanced Scorecard. A rising trend in strategic performance measurement, Measuring Business Excellence, 5(2).

[11] Heery, E., \& Noon, M., (2001). Dictionary of Human Resource Management. Balanced Scorecard. Oxford University Press. Oxford.

[12] Kaplan, R.S. \& Norton, D.P., (1996b). The Balanced Scorecard: Translating Strategy into Action. Harvard Business School Press. Boston. MA.

[13] Tarantino, David P., (2003). Physician executive Nuts and Bolts of Business. Using the Balanced ScoreCard as a performance management tool. 29(5).

[14] Niven, P. R., (2003). Balanced scorecard: Step-by-step for government and nonprofit agencies. Hoboken, NJ: John Wiley \& Sons, Inc.

[15] Garg, R.K. \& Ma. J., (2005).Benchmarking culture and performance in Chinese organizations. Benchmarking, 12(3).

[16] Law, C.C.H. \& Ngai, E.W.T., (2007). ERP systems adoption; An exploratory study of the organizational factors and impacts of ERP success, Information \& Management system, Strategy and Leadership, 33(3).

[17] Banker, R.D., Chang, H. \& Pizzini, M.J. 2004.The balanced scorecard: Judgmental effects of performance measures linked to strategy, Accounting Review, 79(1).

[18] Garrison, R.H., Noreen, G.W., \& Brewer, P.C., (2006). Managerial Accounting. $11^{\text {th }}$ International Edition. NewYork. Mc Graw Hill.

[19] Powell, T.C., (1992).Strategic Planning as Competitive Advantage. Strategic Management Journal (13)7.

[20] Frigo, M.L., \& Litman, J., (2002). What is return driven strategy? Strategic Finance, 83(8).

[21] Davison, L., (2001).Measuring Competitive Intelligence Effectiveness: Insights from the Advertising Industry. Competitive Intelligence Review, 12(4).

[22] Weerawardena, J., (2003). The Role of Marketing Capability in Innovation Based Competitive Strategy. Journal of Strategic Marketing, Vol. 11.

[23] Figueriedo M., (2003). Adoptive Sparseness for Supervised Learning. IEE Transactions on Pattern Analysis and Machine Intelligence, 25 (9).

[24] Kaplan, R.S., (1998). Innovation action research: creating new management theory and practice, Management Accounting Research, 10.

[25] Yahya S., (2001). The Implementation of an ISO 9000 Quality System. International Journal of Quality and Reliability Management. 18(9).

[26] Bashah, S., (2002). Service Quality in local Banks. A Study on Bancassurance Customers. Universiti Sains Malaysia, Penang.

[27] Bungsu, N., (2004). Quality of Services and its Relationship with Customer Loyalty: Perceptions of Audit Clients. Universiti Sains Malaysia, Penang

[28] Fletcher, C., (2004). Appraisal and Feedback: Making Performance Review Work. $3^{\text {rd }}$ Edition. Chartered Institute of Personnel and Development. London

[29] Frigo, M.L., \& Litman, J., (2002). What is return driven strategy? Strategic Finance, 83(8).

[30] Kenya National Bureau of Statistics (2013).Statistics.knbs.or.ke/nada/index/php/catalog

[31] Andy, N., Mike, K., \& Veronica, M.,(2013). Does the BSC work: An empirical investigation. Centre for business performance. Cranfield school of management; Bedfordshire, MK43. OAK, UK.

[32] Barbara, B, \& Eleonora, B., (2010). Performance measurement in the food supply chain; A BSC Approach. University of Parma, Parma, Italy. 28(56).

[33] Sanjoy B, \& Keith T., (2007). Applying the Balanced Scorecard for better performance of Intellectual Capital. Journal of Intellectual Capital, 8(4).

[34] Stephen N.M. Nsuve., \& Gabriel Nyaoga. Application of Balanced Score Card performance measurement at Essar Telecom Kenya Limited. http://ssm.com/abstract=2231330. 